\title{
Effects of substituting ytterbium for scandium on corrosion behaviour of Al-Sc alloy
}

\author{
N. Q. Tuan*, A. C. Alves, F. Toptan, A. B. Lopes \\ and A. M. P. Pinto
}

\begin{abstract}
The localized corrosion and electrochemical behaviour of Al- $0.28 \mathrm{wt} . \% \mathrm{Sc}$ and Al-0.24 wt.\% Sc-0.07 wt.\% Yb alloys have been studied in $3.5 \mathrm{wt} . \% \mathrm{NaCl}$ solution. The results showed that the impurity intermetallic phases containing Fe can act as cathodes and promote localized corrosion in the surrounding matrix. Yb had strong effect on the polarization behaviour in the anodic domain of Al-Sc alloy by improving the pitting corrosion resistance of this alloy. It has been deduced that a high number density of fully coherent nano-sized $\mathrm{Al}_{3} \mathrm{SC}$ or $\mathrm{Al}_{3}(\mathrm{Sc}, \mathrm{Yb})$ precipitates in heat treated alloys can enhance the passivation tendency of these alloys.
\end{abstract}

\section{Introduction}

Sc-containing $\mathrm{Al}$ alloys have some potential for use in automotive, aerospace, and structural applications due to a good mechanical strength, hot cracking resistance and weld strength. A good corrosion resistance also leads them to be potentially applied in saline environment. The effect of Sc on corrosion behaviour has been investigated in various Sccontaining $\mathrm{Al}$ alloys [1-16]. It has been reported that $\mathrm{Sc}$ has a positive effect on the corrosion properties of $\mathrm{Al}$ alloys. The electrochemical properties of coarse $\mathrm{Al}_{3} \mathrm{Sc}$ particle were investigated by Cavanaugh et al. [10] where the influence of these particles on the initiation and propagation of pitting corrosion in Al-2.05 wt.\% Sc alloy exposed to dilute chloride solution was evaluated. The authors reported that $\mathrm{Al}_{3} \mathrm{Sc}$ is slightly cathodic to the $\alpha-\mathrm{Al}$ matrix and spontaneously passivates with a low selfdissolution rate in dilute chloride solution. $\mathrm{Al}_{3} \mathrm{Sc}$ showed slower oxygen reduction reaction kinetics than other dispersoid intermetallic phases as $\mathrm{Al}_{3} \mathrm{Zr}, \mathrm{Al}_{6} \mathrm{Mn}$ and $\mathrm{Al}_{3}$ Ti. Ganiev [1] and Vyazovikina [13] proposed that the passive film in Sc-containing Al alloys consists of duplex layer of scandium oxide and aluminium oxide. $\mathrm{Sc}_{2} \mathrm{O}_{3}$ layer forms by the presence of oxygen in the solution, deposits and accumulates on the surface of alloys.

N. Q. Tuan, A. C. Alves, F. Toptan, A. M. P. Pinto

CMEMS-UMinho - Center for MicroElectroMechanical Systems Universidade do Minho, Azurém 4800-058, Guimarães, (Portugal)

E-mail: quoctuan1884@gmail.com

F. Toptan, A. M. P. Pinto

Universidade do Minho, Dept. Eng. Mecânica, Azurém, 4800-058, Guimarães, (Portugal)

A. B. Lopes

CICECO - Department of Materials and Ceramic Engineering, University of Aveiro, 3810-193, Aveiro, (Portugal)
In comparison with the less defective $\mathrm{Al}_{2} \mathrm{O}_{3}$ layer, the duplex layer in Sc-containing $\mathrm{Al}$ alloys has more protective property. As a consequence, the corrosion resistance in these alloys was improved.

Ahmad and Aleem [17] studied the effect of Sc on mechanical properties and corrosion resistance of $\mathrm{Al}-2.5 \mathrm{Mg}$ alloys doped with Sc and $\mathrm{Zr}$ and reported that the homogeneous coherent nano $\mathrm{Al}\left(\mathrm{Sc}_{1-\mathrm{x}} \mathrm{Zr}_{\mathrm{x}}\right)$ precipitates increased the passivation tendency and improve the corrosion resistance of alloys. It was also suggested that the formation of protective $\mathrm{Sc}_{2} \mathrm{O}_{3}$ reinforced $\mathrm{Al}_{2} \mathrm{O}_{3}$ films enhanced the passivity of $\mathrm{Al}-\mathrm{Mg}-\mathrm{Sc}$ alloys. The film was very coherent with the matrix due to the coherency of the nano-precipitates without any discontinuities at the oxide/ electrolyte interface. However, experimental validation is needed to confirm this hypothesis.

Several studies have been performed on the substitution ability of Sc by rare earth metals in order to reduce the cost of alloy production without decreasing its properties [18-20]. Previous study from some of the present authors had demonstrated the similarity on microstructure, hardness and aging behaviour of $\mathrm{Al}-0.24 \mathrm{wt} \% \mathrm{Sc}-0.07 \mathrm{wt} \% \mathrm{Yb}$ alloy in comparison with $\mathrm{Al}-0.28 \mathrm{wt} \% \mathrm{Sc}$ alloy [20]. However, the corrosion behaviour of these alloys is yet to be evaluated. Thus, in the present study, corrosion behaviour of Al-0.28 wt.\% Sc and Al-0.24 wt.\% Sc-0.07 wt.\% Yb alloys was investigated in 3.5 wt.\% $\mathrm{NaCl}$ solution. A particular attention was given to the effect of $\mathrm{Yb}$ addition and age-hardening heat treatment on corrosion behaviour of both alloys.

\section{Experimental procedure}

$\mathrm{Al}-0.28$ wt.\% Sc and $\mathrm{Al}-0.24$ wt.\% Sc-0.07 wt.\% Yb alloys were used in this study. The details of the processing of the alloys were described in the previous publication [20]. Al-0.28 wt.\% Sc and 
Al-0.24 wt.\% Sc-0.07wt.\% Yb alloys were cast by using commercially pure Al (99.83 wt.\% purity), Al-2 wt.\% Sc master alloy and pure $\mathrm{Yb}$ ( $99.99 \mathrm{wt} \%$ purity). The alloys were melted in a graphite crucible using a high frequency induction furnace. For each alloy, pure $\mathrm{Al}$ was firstly melted at $720{ }^{\circ} \mathrm{C} \pm 5$. Then the Al-2 wt.\% Sc master alloy and pure $\mathrm{Yb}$ were added into the melt. The melt was kept at this temperature for 30 minutes and stirred with an alumina rod to ensure homogeneity. The molten alloys were poured into cylindrical copper moulds with $16 \mathrm{~mm}$ in diameter and $80 \mathrm{~mm}$ in length and water cooled. The compositions of the as-cast alloys were measured by X-ray fluorescence spectrometery (Bruker S8 Tiger) and the results are given in Table 1. Age-hardening heat treatment parameters were chosen as $325{ }^{\circ} \mathrm{C}$ for 5 hours due to the previous study [20] of some of the present authors.

Prior to the electrochemical tests the samples were polished with colloidal silica $(0.3 \mu \mathrm{m})$ and cleaned ultrasonically $10 \mathrm{~min}$ in propanol followed by $5 \mathrm{~min}$ in distilled water. The electrochemical tests consisted in open circuit potential (OCP) measurements and potentiodynamic polarisation tests. All electrochemical tests were performed using a conventional three-electrode electrochemical cell adapted from ASTM standard practice G3-89 [21], where 3.5 wt.\% $\mathrm{NaCl}$ was used as the electrolyte. A saturated calomel electrode (SCE) was used as the reference electrode, Pt electrode was used as the counter electrode, and the samples were used as the working electrode, with an exposure area of $0.07 \mathrm{~cm}^{2}$. All potentials are given with respect to SCE. All electrochemical tests were performed by using a Gamry Instruments Reference $600^{\mathrm{TM}}$ Potentiostat controlled by the Gamry Instruments Framwork ${ }^{\mathrm{TM}}$ software (Gamry Instruments, Warminster, PA, USA).

The immersion tests were performed during $96 \mathrm{~h}$ (4 days). OCP was measured just after immersion during $30 \mathrm{~min}$ and after that, for 15 min each day. Potentiodynamic polarisation measurements started from a cathodic potential of $-1.5 \mathrm{~V}$ up to the anodic domain $(0 \mathrm{~V}$ vs. SCE) with a scan rate of $0.5 \mathrm{mV} / \mathrm{s}$. The samples after electrochemical tests were ultrasonically cleaned in hot water to remove the corrosion products. Each test was repeated at least three times and the average value of corrosion potential $\left(\mathrm{E}_{(i=0)}\right)$, pitting potential $\left(\mathrm{E}_{\mathrm{pit}}\right)$, corrosion current density $\left(i_{\text {corr }}\right)$ were determined by using the software program Gamry Echem Analyst (Version 5.61). The $i_{\text {corr }}$ and $\mathrm{E}_{\text {corr }}\left(\mathrm{E}_{(\mathrm{i}=0)}\right)$ were determined by extrapolation of the Tafel lines of each polarisation curve.

Transmission electron microscopy (TEM) and high resolution transmission electron microscope (HRTEM) study of
$\mathrm{Al}-0.28$ wt.\% Sc and $\mathrm{Al}-0.24$ wt.\% Sc-0.07 wt.\% $\mathrm{Yb}$ age-hardening heat treated samples were presented in a previous study [20]. The results for the samples aged at $325{ }^{\circ} \mathrm{C}$ for 5 hours were recalled in this article with some additional observations and analysis. Moreover, a Nano-SEM-FEI Nova 200 FEG/SEM scanning electron microscope equipped with energy dispersive spectrometer (EDS) EDAX-Pegasus X4 M was used to characterize the microstructures of as-cast, heat treated and corroded samples after immersion.

\section{Results and discussion}

\subsection{Microstructure}

\subsubsection{Impurity intermetallic particles}

The morphologies of intermetallic particles in Al-0.28 wt.\% Sc and $\mathrm{Al}-0.24 \mathrm{wt} . \% \mathrm{Sc}-0.07 \mathrm{wt} . \% \mathrm{Yb}$ alloys were observed and the representative SEM images are given in Fig. 1. Chemical compositions of selected intermetallic particles were determined by EDS and the results are listed in Table 2 . It can be seen that the intermetallic particles with rod-like and rounded shapes are uniformly distributed throughout the matrix in both Al-0.28 wt. $\% \mathrm{Sc}$ and $\mathrm{Al}-0.24 \mathrm{wt} . \% \mathrm{Sc}-0.07 \mathrm{wt} . \% \mathrm{Yb}$ alloys. The size range of rod-like particles is $7-15 \mu \mathrm{m}$ in length whereas the size range of rounded particles is $1-3 \mu \mathrm{m}$. Two intermetallic phases were detected in Al-0.28 wt.\% Sc alloy: Al-Sc-Si-Fe (particles marked as "A1" and "A2") and Al-Fe (particle marked as "A3") containing intermetallic phases. $\mathrm{Al}-\mathrm{Sc}-\mathrm{Yb}-\mathrm{Si}-\mathrm{Fe}-\mathrm{Cu}$ (particles marked as "B1", "B2", and "B3"), Al-Sc-Yb-Fe-Cu (particle marked as "B4") containing intermetallic phases were observed in Al-0.24 wt.\% Sc-0.07 wt.\% Yb alloy. The age-hardening heat treatment did not affect significantly these intermetallic particles, thus they were also detected in heat treated samples of both alloys.

\subsubsection{Nano-precipitates in the heat treated alloys}

The representative TEM and high resolution TEM micrographs of $\mathrm{Al}-0.28 \mathrm{wt}$ \% Sc and $\mathrm{Al}-0.24 \mathrm{wt} . \% \mathrm{Sc}-0.07 \mathrm{wt} . \% \mathrm{Yb}$ alloys aged at $325{ }^{\circ} \mathrm{C}$ for $5 \mathrm{~h}$ are shown in Fig. 2. The average diameter of $\mathrm{Al}_{3} \mathrm{Sc}$ precipitates in $\mathrm{Al}-0.28 \mathrm{wt}$.\% Sc alloy is around $4.3 \mathrm{~nm}$ and this value for $\mathrm{Al}_{3}(\mathrm{Sc}, \mathrm{Yb})$ precipitates in $\mathrm{Al}-0.24 \mathrm{wt}$.\% $\mathrm{Sc}-0.07 \mathrm{wt}$. $\% \mathrm{Yb}$ alloy is around $4.5 \mathrm{~nm}$. The appearance of these precipitates in $\mathrm{Al}-0.28$ wt.\% Sc and $\mathrm{Al}-0.24$ wt.\% Sc-0.07 wt.\% Yb alloys led them to the highest hardness with the Vickers hardness values of $72 \pm 3$ and $74 \pm 3 \mathrm{HV}$, respectively, while the Vickers hardness values of $\mathrm{Al}-0.28$ wt.\% Sc and $\mathrm{Al}-0.24$ wt.\% Sc-0.07 wt.\% Yb

Table 1. Chemical composition of the as-cast alloys

\begin{tabular}{lccccccccrrr}
\hline Alloy & & $\mathrm{Sc}$ & $\mathrm{Yb}$ & $\mathrm{Si}$ & $\mathrm{Fe}$ & $\mathrm{Ni}$ & $\mathrm{Cu}$ & $\mathrm{Ba}$ & $\mathrm{Mn}$ & $\mathrm{Ti}$ & $\mathrm{Al}$ \\
\hline Al-Sc & wt.\% & 0.283 & - & 0.383 & 0.130 & 0.010 & 0.007 & 0.060 & 0.010 & 0.009 & $\mathrm{Bal}$ \\
& at.\% & 0.170 & & 0.369 & 0.063 & 0.005 & 0.003 & 0.012 & 0.005 & 0.005 & $\mathrm{Bal}$ \\
& & & & & & & & & & & \\
\hline Al-Sc-Yb & wt.\% & 0.243 & 0.068 & 0.328 & 0.208 & 0.040 & 0.032 & 0.015 & - & - & $\mathrm{Bal}$ \\
& at.\% & 0.146 & 0.011 & 0.316 & 0.101 & 0.018 & 0.014 & 0.003 & - & - \\
\hline
\end{tabular}



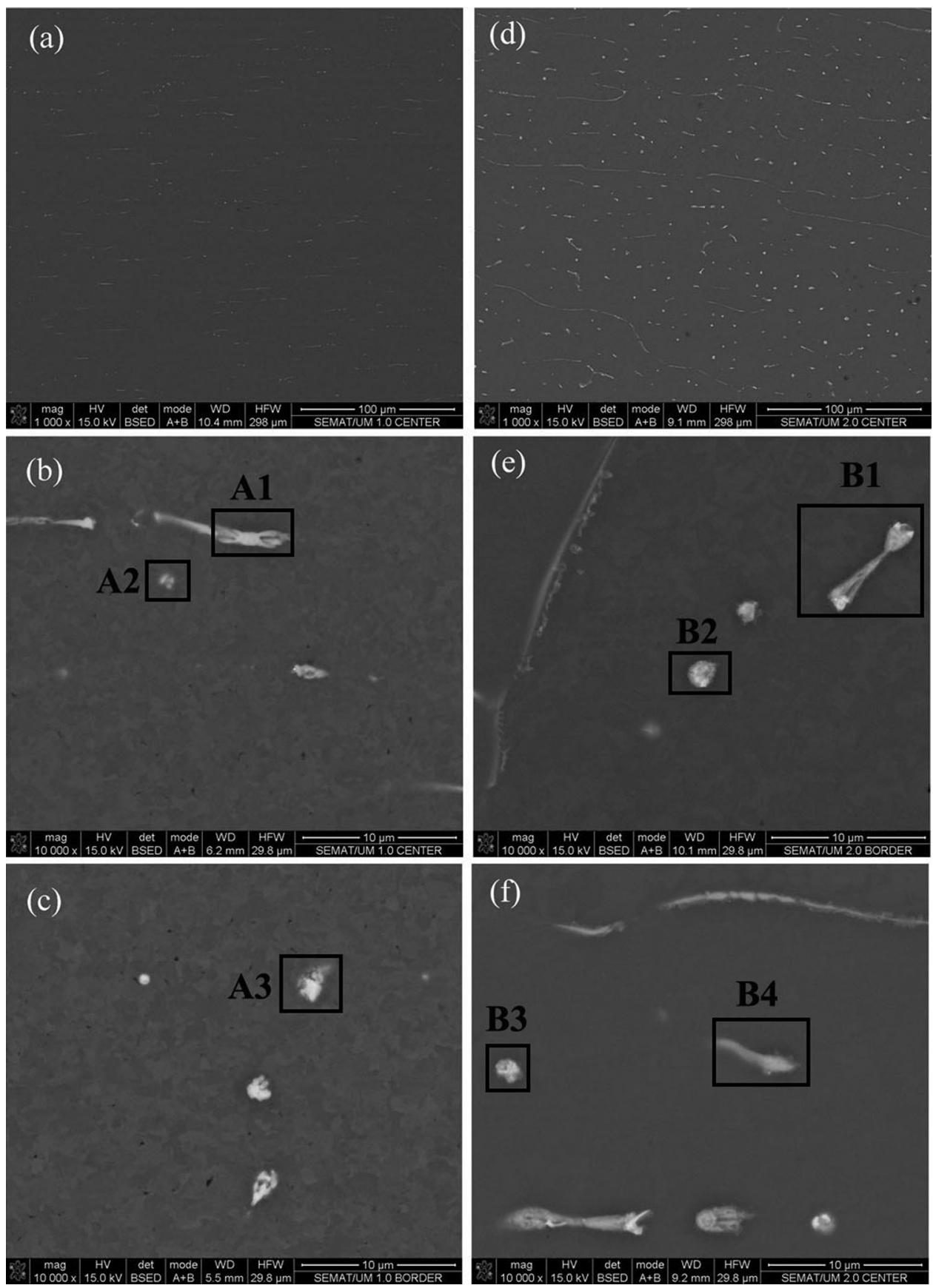

Figure 1. Representative SEM micrographs of Al-0.28 wt.\% Sc alloy (a-b-c) and Al-0.24 wt.\% Sc-0.07 wt.\% Yb alloy (d-e-f).

Table 2. Chemical compositions of intermetallic particles in Al- $0.28 \mathrm{wt} . \% \mathrm{Sc}$ and $\mathrm{Al}-0.24 \mathrm{wt} . \% \mathrm{Sc}-0.07 \mathrm{wt} . \% \mathrm{Yb}$ alloys

\begin{tabular}{|c|c|c|c|c|c|c|c|}
\hline Intermetallic Particle & & $\mathrm{Al}(\mathrm{wt} . \%)$ & Sc (wt.\%) & $\mathrm{Yb}($ wt. \%) & $\mathrm{Fe}($ wt.\%) & $\mathrm{Si}$ (wt.\%) & $\mathrm{Cu}($ wt. $\%)$ \\
\hline \multirow{3}{*}{$\mathrm{Al}-0.28 \mathrm{wt} . \% \mathrm{Sc}$} & A1 & 87.31 & 1.97 & - & 8.06 & 2.67 & - \\
\hline & A2 & 89.92 & 1.31 & - & 7.49 & 1.28 & - \\
\hline & A3 & 91.9 & - & - & 8.1 & - & - \\
\hline \multirow[t]{4}{*}{$\mathrm{Al}-0.24$ wt. $\%$ Sc- 0.07 wt. $\% \mathrm{Yb}$} & $\mathrm{B} 1$ & 78.28 & 0.67 & 5.24 & 9.7 & 2.33 & 3.77 \\
\hline & $\mathrm{B} 2$ & 79.27 & 0.8 & 4.0 & 10.14 & 2.93 & 2.86 \\
\hline & B3 & 76.76 & 1.31 & 6.64 & 9.01 & 3.94 & 2.35 \\
\hline & B4 & 83.36 & 0.55 & 3.27 & 9.97 & - & 2.86 \\
\hline
\end{tabular}


(a)
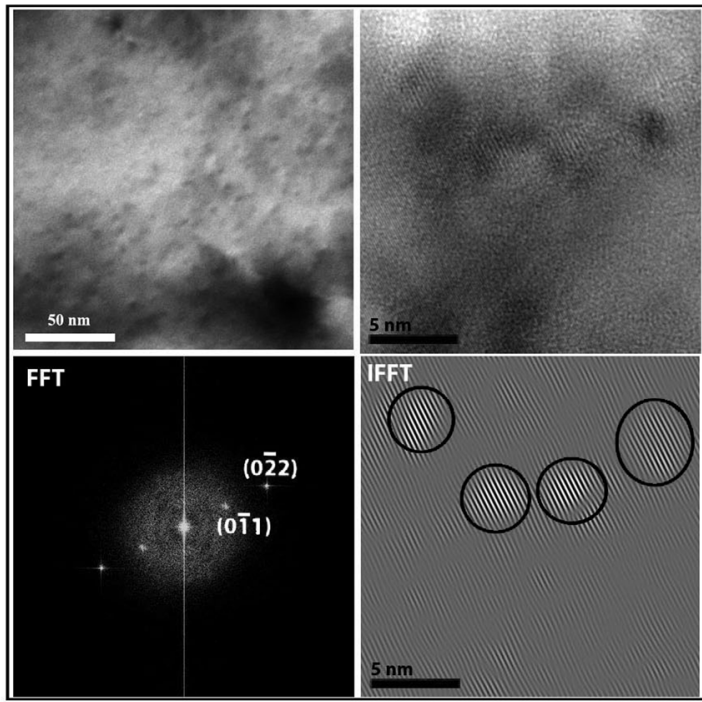

(b)
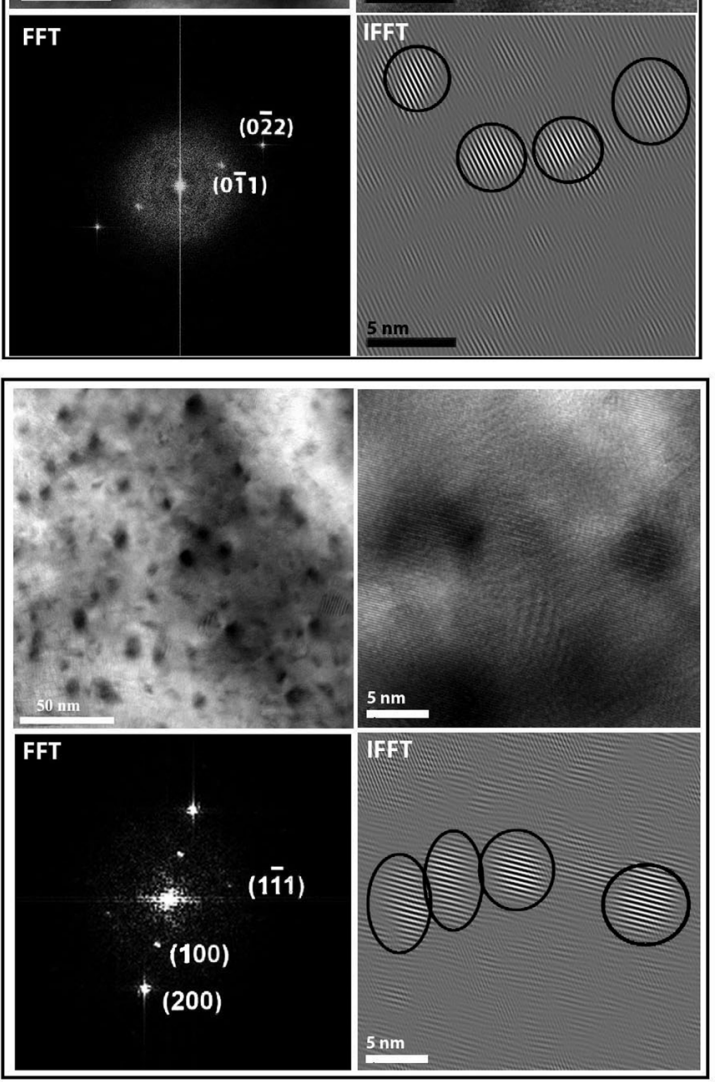

Figure 2. TEM, high resolution TEM micrograph, FFT pattern, and IFFT reconstructed micrograph of Al-0.28 wt.\% Sc (a) and Al - 0.24 wt.\% Sc $-0.07 \mathrm{wt}$ \% $\mathrm{Yb}$ (b) alloys aged at $325^{\circ} \mathrm{C}$ for $5 \mathrm{~h}$.

as-cast alloys were $23 \pm 2$ and $25 \pm 1 \mathrm{HV}$, respectively. The HRTEM images exhibited the full coherency of $\mathrm{Al}_{3} \mathrm{Sc}$ and $\mathrm{Al}_{3}(\mathrm{Sc}$, $\mathrm{Yb}$ ) precipitates with the $\alpha-\mathrm{Al}$ matrix where no interfacial misfit dislocations were observed. The [011] zone axis orientation was found to fit well to the simulation of the reciprocal lattice section at the orientation. The FFT pattern shows the reflections from (100) and $(0 \overline{1} 1)$ of $\mathrm{L1}_{2} \mathrm{Al}_{3} \mathrm{Sc}$ and $\mathrm{Al}_{3}(\mathrm{Sc}, \mathrm{Yb})$ precipitates and the reflections from (200), $0 \overline{2} 2$, and $(0 \overline{1} 1)$ of $\alpha-\mathrm{Al}$. The inverse fast Fourier transform (IFFT) obtained by applying masks near reflections from (100) and (011) could show much better contrast for precipitates identification.

\subsection{Corrosion tests}

\subsubsection{Immersion tests}

Fig. 3 shows the evolution of the OCP with time for Al-0.28 wt.\% Sc and Al-0.24 wt.\% Sc-0.07wt.\% Yb alloys (as-cast and heat

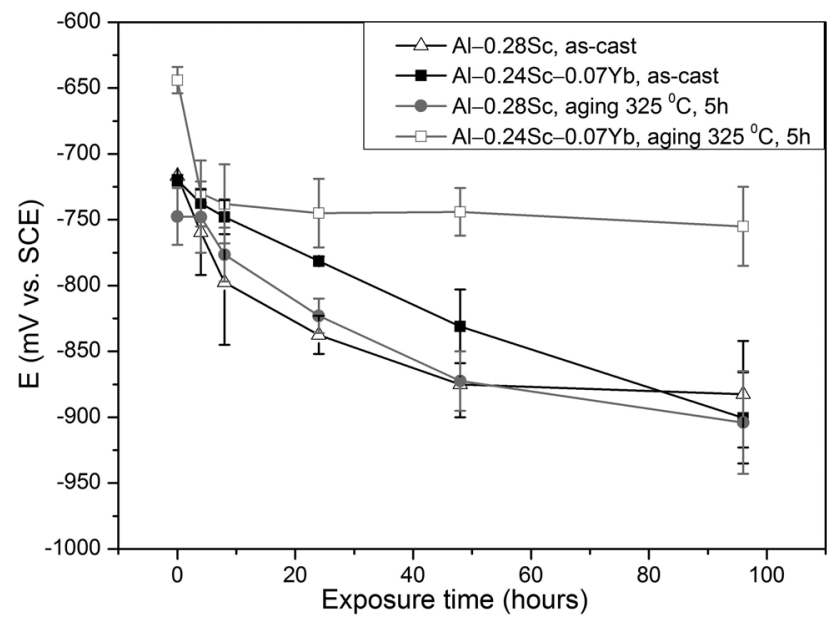

Figure 3. Evolution of OCP with time for Al-0.28 wt.\% Sc and Al$0.24 \mathrm{wt}$.\% Sc-0.07 wt.\% Yb alloys (as-cast and heat treated samples).

treated samples) immersed in $3.5 \mathrm{wt} \% \% \mathrm{NaCl}$ solution. After exposing all samples to the solution the OCP started to decrease. After 4 days of immersion, the OCP of Al-0.28 wt.\% Sc (as-cast and heat treated samples) and $\mathrm{Al}-0.24 \mathrm{wt} . \% \mathrm{Sc}-0.07 \mathrm{wt} \% \mathrm{Yb}$ (as-cast sample) were measured as $-883 \pm 41,-901 \pm 35$, and $-904 \pm 39 \mathrm{mV}$ vs. SCE, respectively. There was no significant difference between these values suggesting similar electrochemical state of these samples in $3.5 \mathrm{wt} . \% \mathrm{NaCl}$ solution. However, Al-0.24 wt.\% Sc-0.07wt.\% Yb heat treated sample stabilized at relatively higher potentials $(-755 \pm 30 \mathrm{mV}$ vs. SCE) after 4 hours of immersion.

Fig. 4 shows the representative SEM micrographs of Al- 0.28 wt.\% Sc as-cast and heat treated samples exposed to $3.5 \mathrm{wt} . \% \mathrm{NaCl}$ solution during 4 days. Chemical compositions of three selected intermetallic particles were determined by EDS and listed in Table 3. The particles marked as "C1" contain $\mathrm{Al}$ and $\mathrm{Fe}$, the particle " $\mathrm{C} 2$ " contain $\mathrm{Al}, \mathrm{Sc}$, and $\mathrm{Fe}$, and the particle " $\mathrm{C} 4$ " contain $\mathrm{Al}, \mathrm{Sc}, \mathrm{Fe}$, and Si. Microstructural observations revealed the dissolution of the matrix surrounding these Fe-containing intermetallic phases. These particles are more noble in comparison with the matrix that can act as cathodes causing formation of a galvanic coupling with the surrounding matrix as

Table 3. Chemical compositions of intermetallic particles in Al-0.28 wt. $\%$ Sc alloy after immersion in a $3.5 \mathrm{wt}$.\% $\mathrm{NaCl}$ solution for 4 days

\begin{tabular}{lcccccc}
\hline Intermetallic Particle & & Al & Sc & Fe & Si & O \\
\hline C1 & wt.\% & 78.77 & - & 3.69 & - & 17.54 \\
& at.\% & 71.52 & - & 1.62 & - & 26.86 \\
\hline C2 & wt.\% & 82.17 & 0.67 & 0.98 & - & 16.18 \\
& at.\% & 74.47 & 0.36 & 0.43 & - & 24.74 \\
\hline C3 & wt.\% & 72.71 & 1.27 & 1.75 & - & 24.27 \\
& at.\% & 63.09 & 0.66 & 0.73 & - & 35.52 \\
\hline C4 & & & & & & \\
\hline & wt.\% & 74.15 & 0.72 & 7.53 & 1.49 & 16.10 \\
& at. \% & 69.37 & 0.41 & 3.41 & 1.34 & 25.47 \\
\hline
\end{tabular}



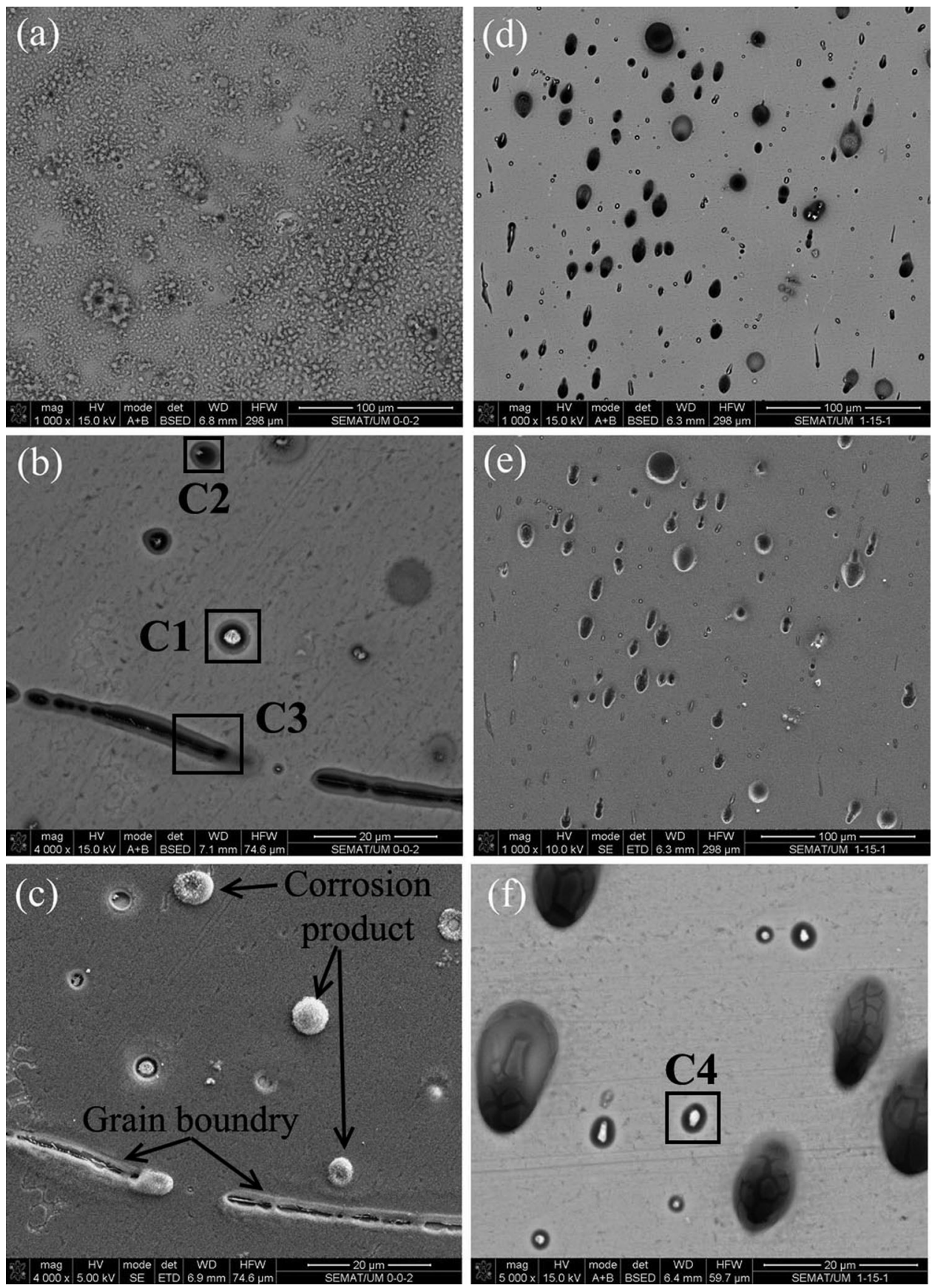

Figure 4. Representative SEM micrographs of Al-0.28 wt.\% Sc alloy after immersion in $3.5 \mathrm{wt} . \% \mathrm{NaCl}$ solution for 4 days: (a-b-c) as-cast samples; $(d-e-f)$ heat treated samples; (a-b-d-f) BSE images and (c-e) SE image.

well as an increase on $\mathrm{pH}$ due to hydroxyl ions forming during oxygen reduction reaction [22,23]. As a consequence, the dissolution of the matrix at the periphery of these particles can occur. The composition in the grain boundary (the area marked as "C3") was also analysed and it was observed that Fe and Sc segregated on the grain boundaries and promoted a slight dissolution of the matrix at these sites. Previous studies have demonstrated that Fe-containing intermetallic particles (such as $\mathrm{Al}_{6} \mathrm{Fe}, \mathrm{Al}_{3} \mathrm{Fe}$ and $\mathrm{Al}_{12} \mathrm{Fe}_{3} \mathrm{Si}_{2}$, etc.) can act as cathodes compared to the matrix and promote the preferential dissolution of the surrounding matrix [22-30]. The corrosion product still remained after cleaning the surface of $\mathrm{Al}-0.28 \mathrm{wt}$.\% Sc as-cast sample (Fig. 4(c)) that might be $\mathrm{Al}(\mathrm{OH})_{3}$ [5]. Similar localized corrosion features were also observed on the SEM micrographs of $\mathrm{Al}-0.24 \mathrm{wt} . \% \mathrm{Sc}-0.07 \mathrm{wt} . \% \mathrm{Yb}$ as-cast and heat treated samples taken after immersion (Fig. 5). Chemical compositions of the particles labelled as "D1" (Al-Sc-Fe-Si intermetallic phase), "D2" (Al-Sc-Yb-Fe-Si intermetallic phase), "D3" (Al-Sc-Yb-Fe intermetallic phase), "D4" (Al-Sc-Fe intermetallic phase) and "D5" (grain boundary containing Al-Sc-Fe) after EDS analysis 

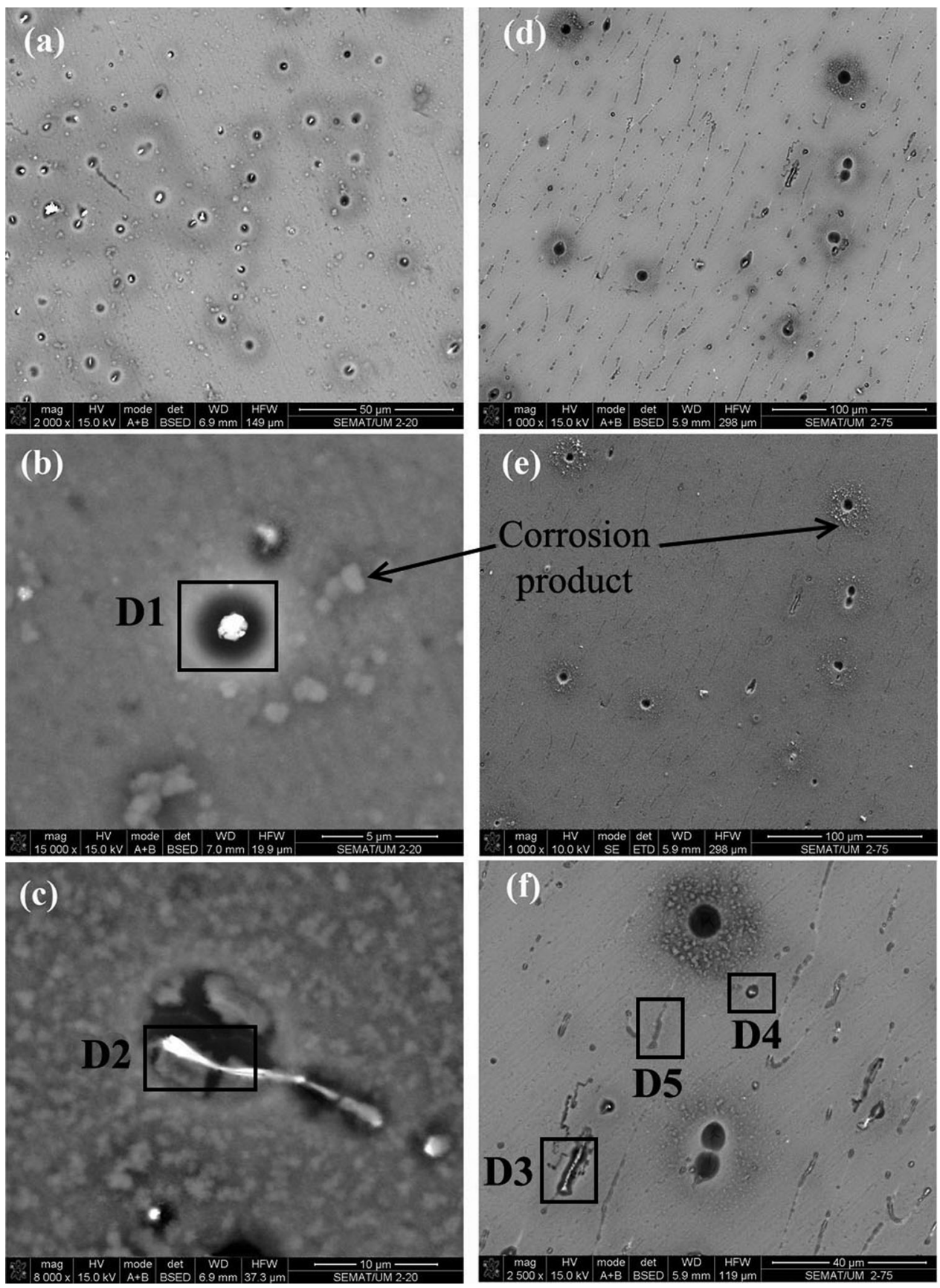

Figure 5. Representative SEM micrographs of Al-0.24 wt.\% Sc-0.07 wt.\% Yb alloy after immersion in $3.5 \mathrm{wt}$.\% $\mathrm{NaCl}$ solution for 4 days: (a-b-c) as-cast samples; (d-e-f) heat treated samples.

were given in Table 4. The dissolution of the matrix was observed in the vicinity of all labelled particles. Moreover, cavities were observed on both alloys after immersion (Figs. 4 and 5).

\subsubsection{Potentiodynamic polarization behaviour}

Representative potentiodynamic polarization curves of $\mathrm{Al}-$ 0.28 wt.\% Sc and $\mathrm{Al}-0.24$ wt.\% Sc-0.07 wt.\% Yb alloys (as-cast and heat treated samples) in $3.5 \mathrm{wt} . \% \mathrm{NaCl}$ solution are shown in Fig. 6. Corrosion potential $\left(\mathrm{E}_{(i=0)}\right)$, corrosion current density $\left(i_{\text {corr }}\right)$ and pitting potential $\left(\mathrm{E}_{\mathrm{p}}\right)$ are listed in Table 5.
It can be seen that after the addition of $\mathrm{Yb}$, the corrosion potential $\left(\mathrm{E}_{(i=0)}\right)$ of $\mathrm{Al}-0.24 \mathrm{wt} \% \mathrm{Sc}-0.07 \mathrm{wt} . \% \mathrm{Yb}$ as-cast and heat treated samples were more positive than Al-0.28 wt.\% Sc ascast and heat treated samples. Yb addition and age-hardening heat treatment had strong effect on the polarization behaviour in the anodic domain of Al-Sc alloy. The polarization curve in the anodic domain of Al- $0.28 \mathrm{wt}$. $\% \mathrm{Sc}$ as-cast sample exhibited active corrosion followed by induced pitting. Al-0.28wt.\% Sc heat treated samples presented active corrosion and passivation followed by induced pitting. On the other hand, Al-0.24 wt.\% 
Table 4. Chemical compositions of intermetallic particles in Al- $0.24 \mathrm{wt} . \% \mathrm{Sc}-0.07 \mathrm{wt} . \% \mathrm{Yb}$ alloy after immersion in a $3.5 \mathrm{wt}$ \% $\mathrm{NaCl}$ solution for 4 days

\begin{tabular}{|c|c|c|c|c|c|c|c|}
\hline Intermetallic Particle & & $\mathrm{Al}$ & $\mathrm{Sc}$ & $\mathrm{Yb}$ & $\mathrm{Fe}$ & $\mathrm{Si}$ & $\mathrm{O}$ \\
\hline \multirow[t]{2}{*}{ D1 } & wt. $\%$ & 76.32 & 0.99 & - & 10.57 & 1.28 & 10.84 \\
\hline & at. $\%$ & 75.16 & 0.59 & - & 5.03 & 1.21 & 18.01 \\
\hline \multirow[t]{2}{*}{ D2 } & wt. $\%$ & 53.60 & 1.52 & 13.16 & 4.39 & 3.22 & 24.10 \\
\hline & at. $\%$ & 52.24 & 0.89 & 2.01 & 2.07 & 3.03 & 39.76 \\
\hline \multirow[t]{2}{*}{ D3 } & wt. $\%$ & 65.57 & 0.53 & 5.46 & 4.44 & - & 24.00 \\
\hline & at. $\%$ & 59.96 & 0.29 & 0.78 & 1.96 & - & 37.01 \\
\hline \multirow[t]{2}{*}{ D4 } & wt. $\%$ & 67.80 & 0.60 & - & 6.34 & - & 25.26 \\
\hline & at. $\%$ & 57.57 & 0.32 & - & 2.69 & - & 37.42 \\
\hline \multirow[t]{2}{*}{ D5 } & wt. $\%$ & 81.05 & 0.49 & - & 1.97 & - & 16.49 \\
\hline & at. $\%$ & 73.61 & 0.27 & - & 0.87 & - & 25.26 \\
\hline
\end{tabular}

Sc-0.07 wt.\% Yb as-cast and heat treated samples exhibited an active region due to metal oxidation with the increasing of current density as applied potential increased. Then, the current density tended to decrease with the increasing of applied potential to reach the passive current density. In the heat treated samples, passivation plateaus were observed before a localized breakdown of passivity due to transpassive dissolution and pitting corrosion. At pitting potential, the current density rapidly

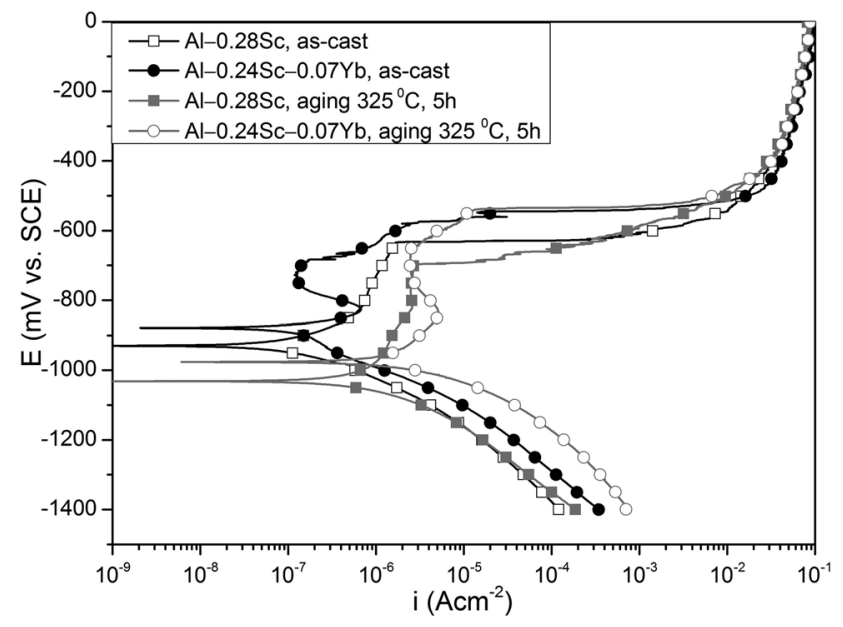

Figure 6. Representative potentiodynamic polarization curves obtained in $3.5 \mathrm{wt}$ \% $\mathrm{NaCl}$ solution for $\mathrm{Al}-0.28 \mathrm{wt} . \% \mathrm{SC}$ and $\mathrm{Al}-0.24 \mathrm{wt} . \%$ $\mathrm{Sc}-0.07 \mathrm{wt} . \% \mathrm{Yb}$ alloys (as-cast and heat treated samples). increased. The pitting potentials of Al-0.28 wt.\% Sc as-cast and heat treated samples were $-632 \pm 42$ and $-679 \pm 33 \mathrm{mV}$ vs. SCE, respectively. The pitting potentials of Al-0.24 wt.\% Sc-0.07 wt.\% $\mathrm{Yb}$ as-cast and heat treated samples were $-565 \pm 24$ and $-521 \pm 19 \mathrm{mV}$ vs. SCE, respectively. The pitting potentials of Al-0.24 wt.\% Sc-0.07 wt.\% Yb alloy (both as-cast and heat treated samples) were more positive than that of Al-0.28 wt.\% Sc alloy. Thus, it can be stated that the addition of $\mathrm{Yb}$ improved the resistance to pitting corrosion of $\mathrm{Al}-0.28 \mathrm{wt}$.\% Sc alloy.

After age-hardening heat treatment, although the corrosion potentials decreased and corrosion current densities increased, polarization curves exhibited passivation plateau for both alloys. Thus, it can be suggested that the age-hardening heat treatment enhanced the passivation tendency of Al-0.28 wt.\% Sc and Al0.24 wt.\% Sc-0.07 wt.\% Yb alloys during exposure to $3.5 \mathrm{wt} . \%$ $\mathrm{NaCl}$ solution, which may be related with the existence of a high number density of nano-sized $\mathrm{Al}_{3} \mathrm{Sc}$ or $\mathrm{Al}_{3}(\mathrm{Sc}, \mathrm{Yb})$ precipitates, which fully coherent with the matrix, led to improvement of the passivity of heat treated samples [17].

Aluminium alloys are susceptible to localized corrosion due to the presence of intermetallic phases more noble than the matrix $[25,26,28,31]$. These particles can act as cathodes and cause preferential dissolution of the surrounding matrix. In addition, the reduction reaction of water and oxygen leads to increase in local $\mathrm{pH}$. The presence of $\mathrm{OH}^{-}$ions can lead to dissolution of the protective oxide layer in the vicinity of these intermetallic particles. As this process continue, detachment of the intermetallic particles took place, leading to cavities on the corroded surfaces [32]. Since OCP values (Fig. 3) were always more negative than the pitting

Table 5. Summary of results of potentiodynamic polarization

\begin{tabular}{lccr}
\hline Alloys & $\mathrm{E}_{(i=0)}(\mathrm{mV})$ & $i_{\text {corr }}\left(\mu \mathrm{Acm}{ }^{-2}\right)$ & $\mathrm{E}_{\mathrm{pit}}(\mathrm{mV})$ \\
\hline Al-0.3Sc, as-cast & $-956 \pm 30$ & $0.296 \pm 0.139$ & $-632 \pm 42$ \\
Al-0.3Sc, aging 325 ${ }^{\circ} \mathrm{C}, 5 \mathrm{~h}$ & $-1038 \pm 8$ & $1.913 \pm 0.596$ & $-679 \pm 33$ \\
Al-0.24Sc-0.06Yb, as-cast & $-884 \pm 6$ & $0.110 \pm 0.02$ & $-565 \pm 24$ \\
Al-0.24Sc-0.06Yb, aging $325{ }^{\circ} \mathrm{C}, 5 \mathrm{~h}$ & $-982 \pm 9$ & $3.281 \pm 0.968$ & $-521 \pm 19$ \\
\hline
\end{tabular}


potential values (Fig. 6) for each sample, it can be stated that the cavities observed on both corroded alloy surfaces after immersion is due to the preferential dissolution of the matrix in the periphery of the intermetallic phases (Figs. 4 and 5). This preferential dissolution was observed on the Fe-containing intermetallic particles, whereas no clear correlation was observed with $\mathrm{Yb}$ content. Instead, as stated above, $\mathrm{Yb}$ addition may result in formation of more stable passive film. However, further studies, particularly electrochemical impedance spectroscopy (EIS) is needed to be performed in order to clarify the effect of $\mathrm{Yb}$ addition to the properties of the passive oxide film. Besides, studying the long term corrosion behaviour with salt spray exposure tests (ASTM B117) can be useful in order to have a better understanding to the corrosion behaviour of these alloys.

\section{Conclusions}

The influence of $\mathrm{Yb}$ addition and age-hardening heat treatment on corrosion behaviour of Al-0.28wt.\% Sc and Al-0.24 wt.\% Sc-0.07 wt.\% Yb alloys was studied. Electrochemical measurements and microstructural investigations revealed that Fecontaining intermetallic phases acted as cathodes and caused preferential dissolution of the surrounding matrix resulting in cavities on the sample during immersion. Polarization curves showed that $\mathrm{Yb}$ addition improved the resistance to pitting corrosion of Al-0.28 wt.\% Sc alloy. On the other hand, although heat treatment led to decreased corrosion potentials and increased corrosion current densities, it enhanced the passivation tendency of both alloys which can be related to the presence of a high number density of fully coherent nano-sized $\mathrm{Al}_{3} \mathrm{Sc}$ or $\mathrm{Al}_{3}(\mathrm{Sc}, \mathrm{Yb})$ precipitates in heat treated alloy.

Acknowledgements: This research was supported by The Project Bridging The Gap, funded by the Erasmus Mundus External Cooperation Window Program. Acknowledgements also to the University of Minho, for the provision of research facilities

\section{References}

[1] I. N. Ganiev, Prot. Met., 1995, 31, 543.

[2] N. V. Vyazovikina, Prot. Met., 1999, 35448.

[3] G. V. Kharina, V. P. Kochergin, Prot. Met., 1996, 32, 134.

[4] V. S. Sinyavskii, V. D. Val'kov, E. V. Titkova, Prot. Met., 1998, 34, 549.
[5] Z. Ahmad, A. Ul-Hamid, A.-A. B. J, Corr. Sci., 2001, 43, 1227.

[6] Z. Ahmad, Mater. Sci. Appl., 2011, 02, 244.

[7] Y.-L. Wu, C. Li, F. H. Froes, A. Alvarez, Metall. Mater. Trans. A, 1999, 30, 1017.

[8] Y. Deng, Z. Yin, K. Zhao, J. Duan, J. Hu, Z. He, Corr. Sci., 2012, 65, 288.

[9] J. Wloka, S. Virtanen, Acta Mater., 2007, 55, 6666.

[10] M. K. Cavanaugh, N. Birbilis, R. G. Buchheit, F. Bovard, Scr. Mater., 2007, 56, 995.

[11] V. Neubert, B. Smola, I. Stulíková, A. Bakkar, J. Reuter, Mater. Sci. Eng. A, 2007, 464, 358.

[12] V. S. Sinyavskii, V. D. Val'kov, E. V. Titkova, Prot. Met., 1998, $34,549$.

[13] N. V. Vyazovikina, Prot. Met., 1999, 35, 448.

[14] G. V. Kharina, V. P. Kochergin, Prot. Met., 2001, 37, 575.

[15] G. V. Kharina, V. P. Kochergin, Prot. Met., 1996, 32, 134.

[16] I. N. Ganiev, Russ. J. Appl. Chem., 2004, 77, 925.

[17] Z. Ahmad, B. J. A. Aleem, Mater. Corros., 2011, 62, 335.

[18] R. A. Karnesky, M. E. van Dalen, D. C. Dunand, D. N. Seidman, Scr. Mater., 2006, 55, 437.

[19] M. E. Dalen, D. C. Dunand, D. N. Seidman, J Mater Sci, 2006, 41, 7814.

[20] N. Q. Tuan, A. M. P. Pinto, H. Puga, L. A. Rocha, J. Barbosa, Mater. Sci. Eng. A, 2014, 601, 70.

[21] ASTM G3-89: Standard practice for conventions applicable to electrochemical measurements in corrosion testing, 1989.

[22] Z. Szklarska-Smialowska, Corr. Sci., 1999, 41, 1743.

[23] N. Birbilis, R. G. Buchheit, J. Electrochem. Soc., 2005, 152, B140.

[24] A. Chemin, D. Marques, L. Bisanha, A. d. J. Motheo, W. W. Bose Filho, C. O. F. Ruchert, Mater. Des, 2014, 53, 118.

[25] N. Birbilis, M. K. Cavanaugh, R. G. Buchheit, Corr. Sci., 2006, 48, 4202 .

[26] A. Aballe, M. Bethencourt, F. J. Botana, M. J. Cano, M. Marcos, Corr. Sci., 2001, 43, 1657.

[27] J. O. Park, C. H. Paik, Y. H. Huang, R. C. Alkire, J. Electrochem. Soc., 1999, 146, 517.

[28] K. Nisacioglu, J. Electrochem. Soc., 1990, 137, 69.

[29] R. Ambat, A. J. Davenport, G. M. Scamans, A. Afseth, Corr. Sci., 2006, 48, 3455.

[30] H. Ezuber, A. El-Houd, F. El-Shawesh, Mater. Des, 2008, 29, 801.

[31] R. Grilli, M. A. Baker, J. E. Castle, B. Dunn, J. F. Watts, Corr. Sci., 2010, 52, 2855.

[32] H.-H. Strehblow, in: Corrosion Mechanisms in Theory and Practice, CRC Press, New York 2011.

(Received: March 22, 2015)

W8360

(Accepted: June 3, 2015) 